\title{
(D) Comparative clinicopathological and OPEN ACCESS immunohistochemical study of micronodular
thymoma and micronodular thymic carcinoma with
lymphoid stroma
}

\author{
Ping Ping Liu $@$, Yun Chao Su, Yun Niu, Yan Fen Shi, Jie Luo, Ding Rong Zhong
}

Department of Pathology, China Japan Friendship Hospital,

Beijing, China

Correspondence to Ding Rong Zhong, China-Japan Friendship Hospital, Beijing, China; zryyblk@163.com

Received 12 July 2021 Accepted 23 August 2021
D) Check for updates

(C) Author(s) (or their employer(s)) 2021. Re-use permitted under CC BY-NC. No commercial re-use. See rights and permissions. Published by BMJ.

To cite: Liu PP, Su YC, Niu Y, et al. J Clin Pathol Epub ahead of print: [please include Day Month Year]. doi:10.1136/

jclinpath-2021-207819

\section{ABSTRACT}

Aim To elucidate the clinicopathological and immunohistochemical characteristics of micronodular thymomas (MNTs) and micronodular thymic carcinomas (MNCs) with lymphoid stroma.

Methods We examined four cases of MNTs and three cases of MNCs pathologically and immunohistochemically.

Results There were prominent cystic changes infive of the seven cases. The neoplasms contained epithelial tumour cells arranged in a micronodular growth pattern lined by cystic walls and separated by abundant lymphoid stroma. Only the tumour cell component of MNCs showed signs of malignancy characterised by cytological atypia and increased mitotic activity. Neoplastic MNC epithelial cells showed strong positivity for CD5 and CD117. However, no immature lymphocytes (TdT-positive and CD99-positive) were present in and around the tumour nodules. None of the patients died or suffered from disease due to MNTs or MNCs.

Conclusion MNTs and MNCs are rare and less aggressive forms of thymic tumours and can be differentially diagnosed by immunohistochemistry.

\section{INTRODUCTION}

The thymus is a unique lymphoepithelial organ that plays a central role in $\mathrm{T}$ lymphocyte development and adaptive immunity. Thymoma is a neoplasm derived from thymic epithelial cells and is associated with variable numbers of non-neoplastic immature $\mathrm{T}$ lymphocytes; however, prominent infiltration of B lymphocytes rarely occurs in any type of thymoma. Micronodular thymomas (MNTs) with lymphoid stroma, originally described by Suster and Moran, ${ }^{1}$ are characterised by multiple small nodules consisting of spindle cells separated by abundant B lymphocytes. They may contain lymphoid follicles with prominent germinal centres. MNTs are an unusual variant of thymoma, accounting for less than $5 \%$ of all thymomas. Micronodular thymic carcinomas (MNCs) with lymphoid hyperplasia, reported by Weissferdt and Moran, ${ }^{2}$ represent the malignant counterparts of MNTs and are rarely encountered. Herein, we report micronodular thymic neoplasms (MNNs) with lymphoid hyperplasia containing both MNTs and MNCs. The aim of this study was to elucidate the clinicopathological and immunohistochemical characteristics of MNTs and MNCs because it is challenging to differentially diagnose these neoplasms.

\section{MATERIALS AND METHODS \\ Patients and tissue samples}

Surgical pathology files at our institution were searched for MNTs and MNCs over the past 10 years (2010-2020), including inpatient and outpatient cases received as consults. Clinical characteristics, including each patient's presentation, clinical history, radiological findings, modality of treatment were obtained from the electronic medical records, and follow-up details by calling the patients or their families. H\&E-stained sections, sections stained for immunohistochemical (IHC) analysis and in situ hybridisation (ISH) for Epstein-Barr virus-encoded RNA (EBER) in each case were reviewed by two pathologists independently. Tumour dimensions were obtained from the gross description. The following features were assessed: tumour size, extent of solid and cystic components, presence and extent of invasion, presence or absence of necrosis, morphology of tumour cells (cell shape, nuclear stain, nucleolus size), number of mitoses per 10 high-power fields (HPF) in the highest proliferative areas, the presence or absence of adjacent conventional thymoma components, the presence or absence of adjacent carcinoma components and the presence and appearance of identifiable adjacent residual non-tumoral thymic tissue. Due to the retrospective nature of the study and the data are anonymous, informed consent was waived.

\section{IHC staining and EBER-ISH}

IHC staining was performed using an automated slide preparation system (BenchMark ULTRA, Tucson, AZ, USA), a biotin-streptavidinenhanced $\mathrm{DAB}$ detection kit and commercially available prediluted monoclonal antibodies (CD3, CD5, CD117, CD20, CD21, CD99, CK19, TdT, epithelial membrane antigen (EMA), CK (AE1/ AE3) and Ki67 (MIB-1)) (all from Ventana Medical Systems, Tucson, Arizona, USA).

EBER-ISH was performed using a BenchMark ULTRA automated immunostainer and ISH iView blue detection kit following the manufacturer's recommendations (Ventana Medical Systems). Protein removal and nucleic acid exposure were performed using ISH protease 3. 
Table 1 Clinicopathological findings of MNNs

\begin{tabular}{|c|c|c|c|c|c|c|c|c|c|}
\hline Case no. & $\begin{array}{l}\text { Age range } \\
\text { (years)/sex }\end{array}$ & Clinical findings & Tumour size (mm) & Gross & $\begin{array}{l}\text { Mitotic } \\
\text { count/10HPF }\end{array}$ & $\begin{array}{l}\text { Fibrous } \\
\text { bands }\end{array}$ & $\begin{array}{l}\text { Tumour cell } \\
\text { atypia }\end{array}$ & Diagnosis & $\begin{array}{l}\text { Follow-up } \\
\text { (months)/ } \\
\text { outcome }\end{array}$ \\
\hline 1 & $\begin{array}{l}\text { Late } 70 \mathrm{~s} / \\
\text { female }\end{array}$ & $\begin{array}{l}\text { Incidental finding during work- } \\
\text { up for anaemia }\end{array}$ & $55 \times 45 \times 30$ & C & $0-1$ & No & No & MNT & $4 / D$ \\
\hline 2 & $\begin{array}{l}\text { Late } 60 s / \\
\text { female }\end{array}$ & $\begin{array}{l}\text { Incidental finding during work- } \\
\text { up for cough }\end{array}$ & $40 \times 40 \times 25$ & C & 1 & No & No & MNT & 51/NED \\
\hline 3 & $\begin{array}{l}\text { Late } 50 \mathrm{~s} / \\
\text { male }\end{array}$ & Incidental finding on CT & $40 \times 25 \times 15$ & C & $0-1$ & No & No & MNT & 16/NED \\
\hline 4 & $\begin{array}{l}\text { Late } 40 \mathrm{~s} / \\
\text { male }\end{array}$ & Myasthenia gravis & $100 \times 78 \times 50$ & $\begin{array}{l}\text { S, rare } \\
\text { micro-C }\end{array}$ & 1 & No & No & MNT & 18/NED \\
\hline 5 & $\begin{array}{l}\text { Early 50s/ } \\
\text { male }\end{array}$ & Incidental finding on CT & $35 \times 35 \times 10$ & C & 2 & Focal & Obvious & MNC & 52/NED \\
\hline 6 & $\begin{array}{l}\text { Late } 40 \mathrm{~s} / \\
\text { male }\end{array}$ & $\begin{array}{l}\text { Incidental finding during work- } \\
\text { up for dizziness }\end{array}$ & $11 \times 10 \times 5$ & C & 5 & Yes & Obvious & MNC & 48/NED \\
\hline 7 & $\begin{array}{l}\text { Late } 50 \text { s/ } \\
\text { male }\end{array}$ & Chest pain & $38 \times 30 \times 20$ & $\begin{array}{l}\text { S, rare } \\
\text { micro-C }\end{array}$ & 7 & Focal & Obvious & MNC & 1/NED \\
\hline
\end{tabular}

All tumours were stage I.

C, cystic; D, death; HPF, high-power field; MNC, micronodular thymic carcinoma; MNN, micro nodularthymic neoplasm; MNT, micronodular thymoma; NED, no evidence of disease; S, solid cystic.

\section{RESULTS}

\section{Clinical findings}

We identified seven cases of MNNs (five male patients and two female patients, aged late 40s to late 70s). The clinical and pathological characteristics of the patients are summarised in table 1. Four of our cases were of MNTs, comprising two male patients and two female patients. Three patients complained of cough, anaemia and myasthenia gravis, prompting further investigation. One patient was asymptomatic, and the tumour was found incidentally on chest radiographs performed during a routine physical examination. The tumour dimensions ranged from 40 to $100 \mathrm{~mm}$.

The other three patients were men aged late $40 \mathrm{~s}$ to late $50 \mathrm{~s}$, and had MNCs. Two patients complained of dizziness and chest pain, prompting further investigation. One patient was asymptomatic, and the tumour was found incidentally on chest radiographs performed during a routine physical examination. The largest dimensions of the tumours measured $11-38 \mathrm{~mm}$.

Thymectomy was performed in all cases. The lesions appeared to be well-circumscribed and encapsulated and were grossly described as cystic masses or solid cystic masses (figures $1 \mathrm{~A}$ and 2A). According to the American Joint Committee on Cancer staging system (2017), all tumours were at stage Ia. Infiltration of the adjacent pleura or lung parenchyma was not observed.
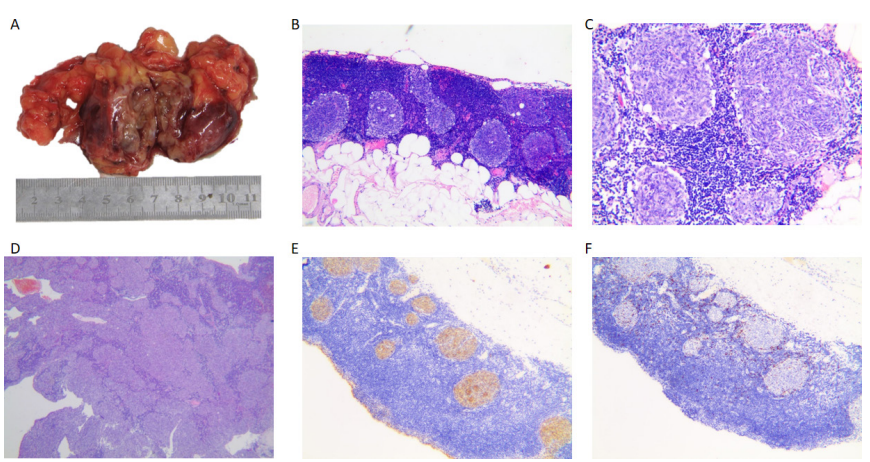

Figure 1 Characteristic features of micronodular thymoma with lymphoid stroma.

\section{Histological and IHC findings}

All MNNs showed similar histological features. Prominent cystic changes were identified in most cases (5/7). The cyst contents were either clear liquid, or old haemorrhages or cholesterol crystals. The tumours contained multiple, discrete, small solid nests or cords of epithelial cells lined by cystic walls, separated by abundant lymphoid stroma (figures $1 \mathrm{~B}$ and $2 \mathrm{~B}$ ). The surrounding lymphoid stroma in all cases was composed of densely populated small lymphocytes and contained numerous lymphoid follicles with germinal centres (figure 2B). Lymphocytes were sparsely distributed with MNNs (figures 1C and 2C). Adjacent residual non-tumoral thymic tissue was atrophic but exhibited some lymphoid follicles.

MNT nodules were composed of short and spindle-shaped cells with scant cytoplasm and oval to elongated uniform nuclei. The nuclei contained dispersed chromatin and relatively indistinct nucleoli (figure 1C). None of the MNTs showed necrosis. Mitoses varied between 0 and 1 per $10 \mathrm{HPFs}$. In one of the MNTs, the micronodules coalesced to form elongated and irregular areas without the presence of thick fibrous septa (figure 1D). Microcystic lesions were found in most areas of the tumour. The cystic portion was lined with cuboidal epithelium transitioned with spindle tumour cells.

Contrary to MNTs, the MNC nodules were composed of large and round to oval-shaped cells with vesicular nuclei, conspicuous
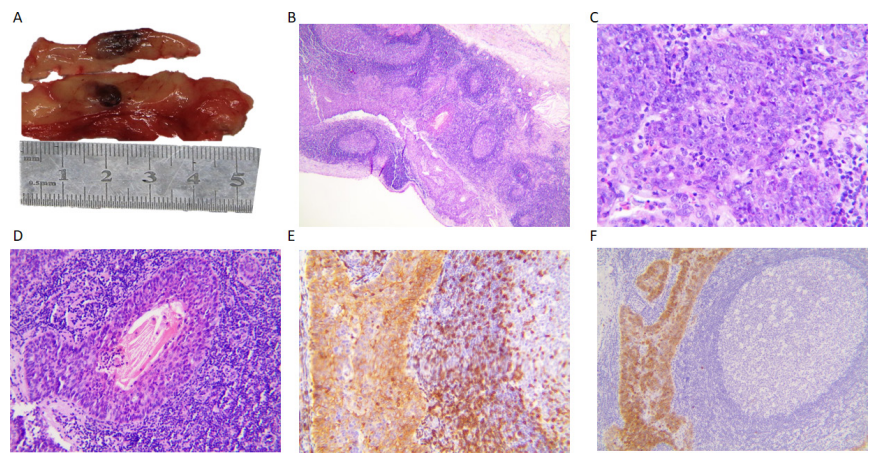

Figure 2 Characteristic features of micronodular thymic carcinoma with lymphoid stroma. 
eosinophilic nucleoli and abundant eosinophilic cytoplasm (figure 2C). Comedonecrosis was observed (figure 2D), and the mitotic activity ranged from 2 to 7 mitoses per 10 HPF. Some areas of the tumour nodules coalesced to form more sheet-like, elongated or solid areas and were separated by thick hyalinised fibrous bands. In some areas of MNCs, there was a lack of lymphoid stroma, similar to that in thymic carcinoma. The cystic portion was lined with large round to oval-shaped tumour cells. No invasion or transformation from MNTs to MNCs was observed in either case.

IHC studies revealed that all MNN epithelial cells had strong positivity for CK19 (figure 1E) and broad-spectrum keratin antibodies (panCK). The surrounding lymphoid cells were composed of large CD20+ B cells and CD3 $+\mathrm{T}$ cells. The cystic lining cells showed strong positive staining for EMA and CK19 (figure 1E). Spindle-shaped MNT cells were negative for CD5 and CD117, with lymphoid stroma in and around the tumour nodules showing scattered positivity for markers of immature lymphocytes (ie, TdT (figure 1F) and CD99). However, MNC epithelial cells showed strong positivity for CD5 (figure 2E) and CD117 (figure 2F). No immature lymphocytes were seen in and around the tumour nodules. Neoplastic epithelial cells of all MNTs and MNCs were CD20 negative. The average number of tumour cells positive for Ki67 (MIB-1) in the MNT and MNC groups were $2 \%$ and $15 \%$, respectively. All MNTs and MNCs tested for the presence of Epstein-Barr virus by EBER-ISH were negative.

\section{Clinical follow-up}

While treatment mainly involved surgical resection, one patient with MNCs received radiation therapy. Clinical follow-up information was available for all patients; one patient with an MNT died for reasons other than thymoma at 4 months, while the remaining patients survived, showing no signs of disease during follow-up periods ranging from 1 to 52 months after complete surgical resection of the lesion.

\section{DISCUSSION}

All MNTs and MNCs in our study were cystic or solid cystic masses. Haemorrhagic changes and areas of infarction and necrosis with cholesterol crystal deposition were observed in the cyst wall.

In 2001, Tateyama et al introduced the concept of a morphological spectrum of micronodular thymic proliferations, varying from benign MNT with lymphoid B cell hyperplasia to MNC with lymphoid hyperplasia. ${ }^{3}$ Since the first description of MNCs, ${ }^{2}$ only a few case reports on MNCs have been published. ${ }^{4}$

However, other studies reported that the cystic characteristics of MNCs were not obvious. ${ }^{2}$ Thymic cysts may reduce the identifiable tumour tissue; therefore, extensive microscopic sampling is important.

MNT nodules were composed of bland spindle-shaped cells, while MNC epithelial cells showed overt cytological atypia and increased mitotic activity. Thick hyalinised fibrous bands in MNCs were also prominent. Mneimneh et al reported transitional morphology between the low-grade micronodular and carcinomatous component in cases of MNC and indicated the possibility of dedifferentiation or transformation rather than de novo development of thymic carcinomas. ${ }^{4}$ However, MNCs in our study did not show transitional morphologies, highlighting the possibility of de novo development of thymic carcinomas.

Thymic carcinomas are CD5 and CD117 positive and TdT negative. ${ }^{5} \mathrm{CD} 117$ positivity is a helpful IHC feature to differentiate thymic carcinomas from mediastinal metastases of carcinomas located elsewhere. We also found the neoplastic epithelial cells of MNCs to be strongly positive for CD5 and CD117, while the spindle-shaped cells of MNTs did not express these markers. CD99 and TdT were expressed at higher levels in the lymphoid stroma of MNTs than in MNCs. Recently, Thomas de Montpreville et al reported that a small panel of antibodies, including those against CD5, CD117 and TdT, were sufficient to confirm the correct diagnosis of MNC and avoid a misdiagnosis of MNT.

MNTs are characterised by multiple small nodules containing type A thymoma-like cells. Previous studies suggested that type A thymomas and MNTs share a common histogenesis with suspected medullary origin. ${ }^{8}$ Immunohistochemically, epithelial cells in up to $70 \%$ of type A thymomas and $90 \%$ of type $\mathrm{AB}$ thymomas were $\mathrm{CD} 20+{ }^{9}$ Previous reports suggested that neoplastic epithelial cells in all MNTs and MNCs were CD20 negative, and we also found the same expression pattern of CD20. Mixed thymomas composed of type A and type B and MNTs have been adequately described previously. ${ }^{141011}$ There were no components of conventional thymomas within our MNTs and MNCs. Careful examination should be performed to exclude combined thymomas, though their occurrence is unusual.

One of the four patients with MNT had myasthenia gravis, which was not found in patients with MNCs. It was hypothesised that lymphoid hyperplasia in MNTs is either a host response to tumour antigens or a tissue response to unrelated intrathymic antigens. Strobel et al reported that the neoplastic epithelium of patients with MNTs expressed high levels of chemokines that can attract dendritic cells, T lymphocytes and B lymphocytes. They concluded that abnormal chemokine expression in tumour cells could promote lymphocyte recruitment to the stroma of MNTs. ${ }^{12}$ However, a high frequency of monoclonal B cell populations $(6 / 18 ; 33 \%)$ was observed in MNTs. ${ }^{13}$ In our cases, T and B lymphocytes were mixed proliferation, and no overwhelming proliferation of B lymphocytes was observed. The possibility of these tumours harbouring low-grade lymphomas should be considered.

The differential diagnosis of MNNs is one of the most challenging issues. Particular attention should be paid to the cytological features of epithelial tumour cells when dealing with MNTs and MNCs. In contrast to MNTs, the tumour cell component of MNCs showed significant signs of malignancy characterised by cytological atypia and increased mitotic activity. Although the malignant epithelial tumour cells demonstrated some morphological features of a lymphoepithelioma-like carcinoma, such as large vesicular nuclei with open chromatin and prominent nucleoli, the lymphoid component was distinctly separated from the tumour nodules. In contrast with the densely populated lymphoid within carcinoma cells in typical lymphoepitheliomalike carcinoma, lymphocytes within tumour nodules were very sparse in MNC. Moreover, the MNNs were not associated with Epstein-Barr virus, while carcinoma cells in lymphoepitheliomalike carcinoma are usually EBER positive. Epithelioid cell granulomatous diseases, such as sarcoidosis may also be identified using KP-1 and panCK as positive and negative markers, respectively.

Consistent with previous reports, ${ }^{4}$ patients with MNNs have a good overall prognosis and rarely die from the disease. Kaminuma et al reported a case of MNT with lymphoid stroma that had local recurrence 10 years after incomplete resection. ${ }^{14}$ This finding indicates that complete thoracoscopic resection of the tumour is a necessary and effective treatment. 
Our findings conclusively indicate that MNTs and MNCs are rare and less aggressive forms of thymic tumours and are gross cystic masses or solid cystic masses. However, our results need validation with larger cohorts and longer follow-ups in future studies. Alike conventional thymic carcinomas, overt cytological atypia is a characteristic feature of the neoplastic epithelial cells of MNCs. Moreover, neoplastic epithelial cells of MNCs show the same IHC expression patterns of CD5, CD117, CD99 and $\mathrm{TdT}$ as in traditional thymic carcinomas.

\section{Handling editor Runjan Chetty.}

Acknowledgements We would like to thank Editage (https://www.editage.com/) for English language editing.

Contributors We certify that we have participated sufficiently in the work to take public responsibility for the appropriateness of the experimental design and method (PPL, DRZ), the collection (YCS), analysis (YN, YFS), interpretation of the data (JL) and writing (PPL).

Funding The authors have not declared a specific grant for this research from any funding agency in the public, commercial or not-for-profit sectors.

Competing interests None declared.

Patient consent for publication Not required.

Ethics approval This study was approved by the ethics committee of the hospital.

Provenance and peer review Not commissioned; externally peer reviewed.

Open access This is an open access article distributed in accordance with the Creative Commons Attribution Non Commercial (CC BY-NC 4.0) license, which permits others to distribute, remix, adapt, build upon this work non-commercially, and license their derivative works on different terms, provided the original work is properly cited, appropriate credit is given, any changes made indicated, and the use is non-commercial. See: http://creativecommons.org/licenses/by-nc/4.0/.

\section{ORCID iD}

Ping Ping Liu http://orcid.org/0000-0003-2133-5371

\section{REFERENCES}

1 Suster S, Moran CA. Micronodular thymoma with lymphoid B-cell hyperplasia: clinicopathologic and immunohistochemical study of eighteen cases of a distinctive morphologic variant of thymic epithelial neoplasm. Am J Surg Pathol 1999;23:955-62.

2 Weissferdt A, Moran CA. Micronodular thymic carcinoma with lymphoid hyperplasia: a clinicopathological and immunohistochemical study of five cases. Mod Pathol 2012;25:993-9.

3 Tateyama H, Saito Y, Fujii Y, et al. The spectrum of micronodular thymic epithelial tumours with lymphoid B-cell hyperplasia. Histopathology 2001;38:519-27.

4 Mneimneh WS, Gökmen-Polar Y, Kesler KA, et al. Micronodular thymic neoplasms: case series and literature review with emphasis on the spectrum of differentiation. Mod Pathol 2015;28:1415-27.

5 Nakagawa K, Matsuno Y, Kunitoh H, et al. Immunohistochemical kit (CD117) expression in thymic epithelial tumors. Chest 2005;128:140-4.

6 Jeong J-H, Pyo J-S, Kim N-Y, et al. Diagnostic roles of immunohistochemistry in thymic tumors: differentiation between thymic carcinoma and thymoma. Diagnostics 2020;10:460.

7 Thomas de Montpreville V, Mansuet-Lupo A, Le Naoures C, et al. Micronodular thymic carcinoma with lymphoid hyperplasia: relevance of immunohistochemistry with a small panel of antibodies for diagnosis-a RYTHMIC study. Virchows Arch 2021. doi:10.1007/s00428-021-03044-2. [Epub ahead of print: 24 Feb 2021].

8 Thomas De Montpréville V, Zemoura L, Dulmet E. [Thymoma with epithelial micronodules and lymphoid hyperplasia: six cases of a rare and equivocal subtype]. Ann Pathol 2002;22:177-82.

9 Pan CC, Chen WY, Chiang H. Spindle cell and mixed spindle/lymphocytic thymomas: an integrated clinicopathologic and immunohistochemical study of 81 cases. Am J Surg Pathol 2001;25:111-20.

10 Cha YJ, Han J, Kim J, et al. A rare case of mixed type A thymoma and micronodular thymoma with lymphoid stroma. J Pathol Trans/ Med 2015;49:75-7.

11 Wang R, Nie L. Mixed type A thymoma and micronodular thymoma with lymphoid stroma. Int J Surg Pathol 2018:26:336-7.

12 Ströbel P, Marino M, Feuchtenberger M, et al. Micronodular thymoma: an epithelial tumour with abnormal chemokine expression setting the stage for lymphoma development. J Pathol 2005;207:72-82.

13 Ishikawa Y, Tateyama H, Yoshida M, et al. Micronodular thymoma with lymphoid stroma: an immunohistochemical study of the distribution of Langerhans cells and mature dendritic cells in six patients. Histopathology 2015;66:300-7.

14 Kaminuma Y, Tanahashi M, Yukiue H, et al. Micronodular thymoma with lymphoid stroma diagnosed 10 years after the first operation: a case report. J Med Case Rep 2019;13:69. 